Jurnal Sastra Indonesia

http://journal.unnes.ac.id/sju/index.php/jsi

\title{
PRINSIP SECUKUPNYA MENGENDALIKAN PERILAKU KONSUMTIF KAJIAN PSIKOLOGI SASTRA PADA NOVEL KELUARGA CEMARA 1
}

\section{Dyah Prabaningrum ${ }^{\bowtie}$, Sofia Nur Khasanah, dan Swarinda Tyaskyesti}

Jurusan Bahasa dan Sastra Indonesia, Fakultas Bahasa dan Seni, Universitas Negeri Semarang, Indonesia

\section{Info Artikel}

\section{Sejarah Artikel:}

Diterima Januari 2019

Disetujui Februari 2019

Dipublikasikan Maret 2019

Keywords:

"sacukupe" concept, consumerism, and character education

Abstrak

Tren konsumtivisme sangat mungkin mempengaruhi penurunan tingkat kebahagian masyarakat. Menurut Cronk (1996) konsumerisme menawarkan kesenangan ego sesaat untuk mereka yang mampu meraih kemewahan, dan menawarkan frustasi bagi mereka yang tidak mampu. Oleh karena itu, masyarakat perlu mendapatkan alternatif sebagai pendidikan karakter untuk mengendalikan perilaku konsumtifnya agar mencapai kebahagiaan. Pendidikan karakter yang demikian dapat dimediumkan dalam bentuk karya sastra. Artikel ini mengkaji tokoh dan penokohan anggota keluarga Cemara yang menerapkan prinsip secukupnya mengendalikan perilaku konsumtif dalam novel Keluarga Cemara 1. Metode penelitian yang digunakan dalam penelitian ini adalah metode psikologi sastra. Hasil dari penelitian ini adalah prinsip secukupnya anggota keluarga cemara tercermin pada sikap yang mendahulukan prioritas dan mencukupkan diri pada hal yang ada.
\end{abstract}

\begin{abstract}
Consumerism nowadays may be a big factor which affect the decrease of happiness. According to Cronk (1996) consumerism brings pleasure to them who can always get things, while it causes stressfull to them who can't. Therefore, people in society nowadays need to get some character education alternatives to manage their consumtive behavior so that happiness can be achieved. One of character education alternatives is education through literacy. This article analyze Keluarga Cemara's figures and their character within novel. We analyze using "sacukupe" concept from Ki Ageng Suryomentaram to manage consumtive behavior in Keluarga Cemara 1 Novel. The method in this current study is using psychology of literacy. The result found that "sacukupe" concept is determined in the attitude of priority first and accept the thing they have had with gratitude.
\end{abstract}




\section{PENDAHULUAN}

Baudrillard (2009) menggam-barkan aktivitas konsumtivisme dalam bukunya yang berjudul "The Consumer Society: Myth and Structure". Ia (2009:26) mendeskripsikan bahwa satu hal yang terlihat menonjol dalam masyarakat saat ini adalah kefantastisan aktifitas konsumsi, disertai berlimpahan barang dan jasa. Hal ini juga sebagai penanda mutasi fundamental dalam ekologi spesies manusia. Tergambar dalam bukunya bahwa manusia di zaman yang telah makmur ini dikelilingi bukan oleh sebagian besar manusia lainnya, akan tetapi oleh benda/objek. Dengan kata lain, menurut Baudrillard, aktivitas keseharian manusia dewasa ini, tidak banyak dilalui dengan hubungan antarmanusia, akan tetapi dengan resepsi dan manipulasi dari barang-barang dan pesan yang terkirim dari media. Individu atau masyarakat yang cenderung konsumtif biasanya melakukan segala sesuatu untuk mendapatkan uang serta untuk meningkatkan gengsi. Nasional Geographic (2017) mengabarkan bahwa usaha peningkatan pendapatan yang dilakukan masyarakat mengalami kenaikan, namun tingkat kebahagiaan masyarakat Indonesia justru mengalami penurunan. Peringkat kebahagiaan penduduk Indonesia tahun 2017 berada pada posisi ke-81, sedangkan pada tahun 2016 di posisi ke-79. Adapun pada tahun 2015 berada pada posisi ke-74 menurut Word Happines Report 2017 (dalam Nasional Geographic 2017).

Tren konsumtivisme sangat mungkin mempengaruhi penurunan tingkat kebahagian masyarakat. Menurut Cronk (1996) konsumerisme menawarkan kesenangan ego sesaat untuk mereka yang mampu meraih kemewahan, dan menawarkan frustasi bagi mereka yang tidak mampu. Masyarakat yang merupakan sekumpulan individu pastinya memiliki fantasi dan kemampuan yang berbeda dalam mengakomodasi fantasinya. Oleh karena itu, masyarakat perlu mendapatkan alternatif sebagai pendidikan karakter untuk mengendalikan perilaku konsumtifnya agar mencapai kebahagiaan.

Pendidikan karakter yang demikian dapat dimediumkan dalam bentuk karya sastra. Dalam karya sastra terdapat tokoh dan penokohan yang dapat dikaji dalam rangka mengupayakan pendidikan karakter bagi pembaca karya. Dalam pandangan Suharianto (2005:31) tokoh dan penokohan termasuk salah satu unsur penting dalam sebuah cerita. Penokohan atau perwatakan melukiskan mengenai tokoh cerita, keadaan lahir-batin: pandangan hidupnya, sikap, keyakinan, adat istiadat, dan sebagainya. Melalui tokoh-tokoh dalam cerita pembaca dapat mengetahui sikap dan ekspresi yang sedang dirasakan oleh tokoh cerita tersebut. Melalui para tokoh itu pulalah peristiwa-peristiwa dalam cerita menjadi terjalin. Peristiwa-peristiwa tersebut mem-bentuk satu keutuhan cerita. Dengan demikian, artikel ini mengkaji tokoh dan penokohan anggota keluarga Cemara yang menerapkan prinsip secukupnya mengen-dalikan perilaku konsumtif dalam novel Keluarga Cemara 1. Hal tersebut dikaji dengan prinsip secukupnya Suryomentaram. Secukupnya berarti apa yang dilakukan tidak lebih dan tidak kurang, pas menurut kuantitas dan kualitas yang diperlukan (Fudyartanto, 2003)

Beberapa artikel yang relevan dengan penelitian ini sebagai berikut. Artikel Fitriyah (2013) yang berjudul "Iklan Televisi dan Perilaku Konsumtif Anak-Anak (Studi Kasus Pada Siswa SDN 13 Serang)". Tulisan tersebut dipublikasi pada Jurnal Al-Azhar Indonesia Seri Pranata Sosial, volume 2, tahun 2. Dalam tulisannya Fitriyah (2013) meneliti hal-hal yang mempengaruhi anak-anak berperilaku konsumtif. Selain itu, skripsi yang ditulis oleh Rosari (2013) yang berjudul "Konsumtivisme Wanita Dewasa Awal pada Tiga Wilayah Konsumsi: Primer, Sekunder, dan Tersier." Penelitian tersebut menunjukkan hasil bahwa pada konsumsi tersier, wanita dewasa awal menginginkan teknologi contoh gawai. Pada konsumsi sekunder, wanita dewasa awal menginginkan fashion. Adapun pada konsumsi primer, mereka menginginkan kudapan (es krim dan makanan ringan).

\section{METODE PENELITIAN}

Penelitian ini berupa penelitian kepustakaan. Objek material yang dijadikan bahan penelitian adalah karya sastra berupa novel Keluarga Cemara 1. Adapun yang akan dikaji adalah tokoh dan penokohan anggota keluarga Cemara yang menerapkan prinsip secukupnya mengendalikan perilaku konsumtif dalam novel Keluarga Cemara 1. Data dan referensi yang digunakan dalam penelitian ini adalah novel Keluarga Cemara 1, buku-buku, jurnal ilmiah, serta sumber dari internet yang terkait dengan prinsip secukupnya Suryomentaram.

Metode penelitian yang digunakan dalam penelitian ini adalah metode psikologi 
sastra. Psikologi sastra mengenal karya sastra sebagai pantulan kejiwaan. Pengarang akan menangkap gejala jiwa kemudian diolah ke dalam teks dan dilengkapi dengan kejiwaannya. Proyeksi pengalaman sendiri dan pengalaman hidup di sekitar pengarang, akan terproyeksi secara imajiner ke dalam teks sastra (Endraswara 2003:96). Oleh karena itu teknik dalam pengkajian adalah sebagai berikut. Teks yang dijadikan objek material dibaca berulangulang untuk diperiksa bagian-bagian yang berpotensi mengungkapkan sikap tokoh yang menunjukkan prinsip secukupnya. Bagianbagian yang telah diidentifikasi kemudian diinterpretasi.

\section{HASIL DAN PEMBAHASAN}

Secukupnya berarti apa yang dilakukan tidak lebih dan tidak kurang, pas menurut jumlah dan kualitas yang diperlukan (Fudyartanto, 2003). Prinsip secukupnya ditujukkan pada bagian narasi berikut. Agil merengek ingin naik kereta gantung di taman mini sementara untuk itu membutuhkan biaya yang tidak sedikit karena harus ke Jakarta. Semua membujuk Agil. Terlihat dalam petikan narasi dalam novel

"Ema mengedipi Ara. Akhirnya mereka berdua diberi uang seratus rupiah. Ara menuntun Agil ke pasar. Maunya membeli es krim. Akan tetapi karena harganya di atas seratus rupiah, Ara memutuskan membeli jolly murahan. Bisa diputus untuk mereka berdua." (Atmowiloto 2013:168)

Dalam situasi tersebut, Ara bertindak secukupnya. Saat ingin membeli es krim tetapi uang tidak mencukupi, Ara memutuskan untuk membeli jolly. Keinginan Ara untuk membeli es krim kemudian mungkret menjadi jolly. Di sini Ara merasa cukup dengan makan jolly. Konsep secukupnya dari Suryomentaram dalam situasi ini sesuai dengan yang dikemukakan Ramnya dan Ali (2016:77) bahwa perilaku konsumtif dipengaruhi oleh seberapa kemampuan otak untuk memilah informasi yang ada di lingkungannya. Semakin otak mampu menyeleksi kebutuhan prioritas, maka perilaku konsumtif dapat dikendalikan.

Kemampuan menyeleksi prioritas untuk mengendalikan perilaku konsumtif ternyata dimiliki juga oleh Euis. Tampak pada saat uang pemberian Tante Iyos yang sedianya untuk membeli sepatu digunakan untuk membayar hutang. Ara menangis dan Euis menghibur. Terlihat dari kutipan berikut

"Duitnya tidak hilang. Tadi dipakai Ema untuk membayar Aceuk Salmah." Cemara menangis. Melap dengan punggung tangannya.

"Ema, aku, Abah risi melihat Aceuk Salmah. Aku dimintai pendapat, aku setuju. Tak bisa lain, Ara. Kalau tidak dibayar sekarang, Aceuk marah-marah, seluruh kampung diberi tahu. Bunganya juga makin tinggi. Nanti kalau tabungan kita sudah penuh, kita beli yang baru ya? Ya?" (Atmowiloto, 2013: 38)

Di dalam kutipan tersebut, Euis menghibur Ara dan secara tidak langsung memberi contoh kepada Ara untuk merasa cukup. Euis mampu untuk menyeleksi prioritas kebutuhan. Membayar hutang lebih menjadi prioritas di atas keinginan membeli sepatu. Ara masih memiliki sepatu meskipun terasa tidak enak dipakai. Dengan demikian Euis mengajarkan untuk mengendalikan perilaku konsumtif, sekaligus juga mengajarkan kepada Ara mengenai nilai sacukupe dalam konsep Suryomentaram.

Kemampuan Ara dan Euis dalam menyeleksi kebutuhan prioritas untuk mengendalikan perilaku konsumtif tentu saja tidak terlepas dari didikan Abah kepada anakanaknya. Abah seringkali memberikan contoh kepada anak-anaknya untuk tidak berlebihan dalam berperilaku konsumtif. Salah satunya tampak pada saat suatu sore, Abah mengajak Ara dan Agil berjalan-jalan supaya tidak mengganggu pekerjaan Ema dan Euis. Ara bertanya ke mana mereka hendak pergi dan Abah menjawab bahwa mereka sekedar berjalan-jalan saja. Ara kemudian mengemukakan keinginannya untuk membeli jajan. Tampak pada percakapan antara Abah dan Ara.

\footnotetext{
"Ke pasar saja, Bah"

"Boleh"

"Beli es?"

"Tidak usah"

"Beli bakso?"

"Ema kan sudah masak"

"Ara ingin bakso"

"Agil juga ingin, Bah"

"Lain kali saja. Sekali ini benar-benar jalan-jalan. Kalian harus tahu, bahwa jalan-jalan ini juga menyenangkan. Lebih menyenangkan daripada beli
} 
bakso. Makan terus kan bosan." (Atmowiloto 2013:68)

Dalam situasi tersebut, Ara ingin membeli jajan entah itu es atau bakso. Akan tetapi Abah menolak karena Ema sudah masak di rumah. Abah mengajarkan kepada Ara dan Agil untuk mengendalikan perilaku konsumtif, sekaligus juga untuk merasa cukup dengan makanan yang sudah mereka miliki yaitu makanan yang dimasak oleh Ema. Tidak usah membeli lagi makanan. Karena pada dasarnya, tujuan makan adalah untuk merasa kenyang dan masakan Ema sudah cukup untuk membuat seluruh anggota keluarga kenyang. Dengan demikian Abah mengajarkan konsep Suryomentaram yaitu secukupnya.

Hal lain yang terkait prinsip secukupe yang dapat mengendalikan perilaku konsumtif adalah berikut. Saat Ara menceritakan kepada Abah bahwa Lukas akan dibelikan piano. Waktu itu, Ara dan Lukas akan mengikuti perlombaan menyanyi. Di sekolah, Lukas bercerita bahwa ia akan dibelikan piano oleh ayahnya apabila memenangkan perlombaan. Di rumah, Ara menanyakan kepada Abah apakah Ara juga akan mendapatkan hadiah serupa. Abah menjawab pertanyaan Ara dengan bijak. Tampak pada kutipan berikut.

"Dari dulu abah bilang, bukan hadiahnya yang utama. Kalau abah bisa membelikan piano, abah tidak menunggu kamu jadi juara. Kan bisa untuk latihan sebelumnya." (Atmowiloto 2013:105).

Dalam kedua situasi tersebut, Abah menanamkan kepada Ara untuk memiliki konsep cukup. Bahwa ketika memenangkan sebuah kompetisi, kita hendaknya merasa cukup dengan apapun hadiah yang diterima, tidak menuntut lebih. Sikap cukup dan tidak menuntut lebih membuat seseorang mampu mengendalikan perilaku konsumtifnya.

Selain itu, prinsip secukupe dapat dilihat saat Ara tidak risau saat tidak membeli baju baru untuk merayakan Natal. Perayaan Natal identik dengan bermacam hiasan yang berkelapkelip dan barang-barang yang baru. Tidak demikian dengan keluarga Ara. Tidak ada hiasan apapun dan baju baru. Tampak pada kutipan penggambaran sebagai berikut.

"Ara sendiri tidak risau. Untuk natal nanti, ia masih bisa memakai gaun
Cinderela biru yang sudah dipakai tahun lalu. Yang dipakai perdana ketika masuk sekolah itu. Bagi Ara, gaun itu selalu baru. Dan sesungguhnya hanya untuk saat saat istimewa seperti itulah gaun itu dipakai" (Atmowiloto 2013:112).

Dalam situasi tersebut, tergambar bahwa Ara memiliki konsep secukupnya. Ara merasa cukup dengan baju-baju yang sudah ia miliki dan ia merasa istimewa untuk itu. Ara tidak menuntut dibelikan baju baru seperti teman-teman atau kebanyakan orang lainnya. Ara merasa cukup dan memikirkan keberkahan yang ia dapat dalam hidupnya. Ara menganggap bahwa memiliki gaun adalah suatu keberkahan meskipun hanya sebuah. Rasa cukup tersebut memunculkan rasa bahagia yang dapat mengendalikan perilaku konsumtif.

\section{PENUTUP}

Konsumtivisme dapat dikendalikan dengan berprinsip dan bersikap secukupnya. Secukupnya yang berarti menginginkan dan mengambil sesuatu yang diperlukan dengan takaran yang pas. Sikap Abah yang mengajarkan pada anggota keluarga untuk berprinsip secukupnya dan menjelaskanalasan dari pengambilan sikap tersebut patut diteladani. Begitupun kemampuan Euis, Ema, dan Ara menyeleksi kebutuhan berdasarkan skala prioritas merupakan perilaku yang dapat mengendalikan ego konsumtif.

\section{DAFTAR PUSTAKA}

Atmowiloto, Arswendo. 2017. Keluarga Cemara 1. Jakarta: Gramedia.

Baudrillard, Jean. 2009. "The Consumer Society: Myth and Structure". London. Sage Publication.Ltd.

Cronk, Rip. 1996. "Consumerism and the New Capitalism." Art On The Rebound A Collection Of Essays On Art And Culture. Westland Network.

Endraswara, Suwardi. 2003. Metodologi Penelitian Sastra (Epistemologi, Model, Teori, dan Aplikasi). Yogjakarta: Universitas Negeri Yogyakarta.

Fitriyah, Neka. 2013. "Iklan Televisi dan Perilaku Konsumtif Anak-Anak (Studi Kasus Pada Siswa SDN 13 Serang)". 
Jurnal Al-Azhar Indonesia Seri Pranata Sosial. 2.2: 110-118.

Fudyartanto, Ki. 2003. Psikologi Kepribadian Timur. Yogyakarta: Pustaka Pelajar.

Nasional Geograpic. 2017. Inilah Negara-negara Paling Bahagia di Dunia Tahun 2017. http://nationalgeographic.co.id/berita/201 7/03/inilah-negara-negara-paling-bahagiadi-dunia-tahun-2017 (diunduh pada tanggal 19 Februari 2018).

Ramya, N., Ali, S.A.M. (2016). Factors affecting consumer buying behavior. International Journal of Applied Research, 2,10: 76-80.

Rosari, Evrita. 2013. "Konsumtivisme Wanita Dewasa Awal pada Tiga Wilayah Konsumsi: Primer, Sekunder, dan Tersier." Skripsi. Universitas Sanata Darma.

Suharianto, S. 2005. Dasar-Dasar Teori Sastra. Semarang: Rumah Indonesia. 